\title{
Mimicking hypersensitivity pneumonitis as an uncommon initial presentation of chronic granulomatous disease in children
}

\author{
Hui Liu', Jinrong Liư', Huimin Li ${ }^{1}$ Y Yun Peng ${ }^{2}$ and Shunying Zhao ${ }^{1 *}$
}

\begin{abstract}
Dry cough, dyspenea and diffuse centrilobular nodules in both lungs of radiologic findings similar to hypersensitivity pneumonitis (HP) are rare initial presentation in chronic granulomatous disease (CGD). CGD is remarkable for increased susceptibility to bacterial and fungal infections as well as high sensitivity to inciting antigens such as Aspergillus species due to dysregulated inflammation. We identified three children who had an initial presentation mimicking HP and were subsequently diagnosed as CGD. All patients developed invasive pulmonary A. fumigatus infection (IPAI) following systemic glucocorticoid therapy. Two of the three patients were found to have mutations in NCF1 gene and one patient in NCF2 gene. As HP is uncommon in children, we should consider the possibility of CGD in children with HP, even in mimicking HP patients with suggestive inhalation history and negative fungal cultures. A prompt diagnosis of CGD is essential to enable initiation of prophylactic antibacterial and antifungal therapies.
\end{abstract}

Keywords: Chronic granulomatous disease, Hypersensitivity pneumonitis, A. fumigatus, Glucocorticoid, Children

\section{Letter to the editor}

Chronic granulomatous disease (CGD) is characterized by recurrent and severe bacterial and fungal infections as well as excessive inflammation, which are most prominent in gastrointestinal and genitourinary tracts, such as granulomata mimicking Crohn's disease [1].

An exuberant respiratory inflammation induced by the exposure to inciting antigens and clinically manifested as hypersensitivity pneumonitis (HP) or allergic bronchopulmonary aspergillosis (ABPA) has also been described in CGD [2-7]. However, HP as an initial presentation of CGD is uncommon and has never been reported. Here we review three children who had an initial presentation mimicking HP, developed invasive pulmonary A. fumigatus infection (IPAI) following systemic glucocorticoid therapy and were subsequently diagnosed as CGD.

\footnotetext{
* Correspondence: zhaoshunyingdoc@sina.com

'Department of Respiratory Medicine, Beijing Children's Hospital, Capital Medical University, National Center for Children's Health, Nanlishi Road 56, Xicheng District, Beijing, China

Full list of author information is available at the end of the article
}

\section{Case presentation}

\section{Case 1}

A 4-year-old boy was admitted to the hospital on September 8, 2011 after 3 weeks of dry cough, progressive dyspnea and fever. He lived in a fruit stall with many rotten fruits inside. He had a history of pneumonia at 3 months old. He also had a history of severe eczema and seasonal rhinitis at one year old.

On admission, his oxygen saturation at rest was $92 \%$, and decreased to $86 \%$ after walking. Bilateral basilar rales were noted on auscultation. Chest high-resolution CT (HRCT) scan showed diffuse nodular opacities and slight ground-glass (Fig. 1a). Cultures revealed no evidences of mycobacteria, fungi and viruses. A specimen taken from video-assisted lung biopsy of the right lower lobe revealed bronchiolo centric lymphocytic, and nonnecrotizing granulomas and no evidence of fungal or bacterial elements (Fig. 2). Bronchoalveolar lavage fluid (BALF) from his right middle lobe consisted of $46 \%$ macrophages, $2 \%$ eosinophils and $52 \% \mathrm{~T}$ cells, with a $\mathrm{CD}^{+} / \mathrm{CD}^{+}$ratio of 0.62 . Fungal and mycobacterial cultures of BALF were negative, as were T-cell interferon$\gamma$ release assays for tuberculosis and polymerase chain 

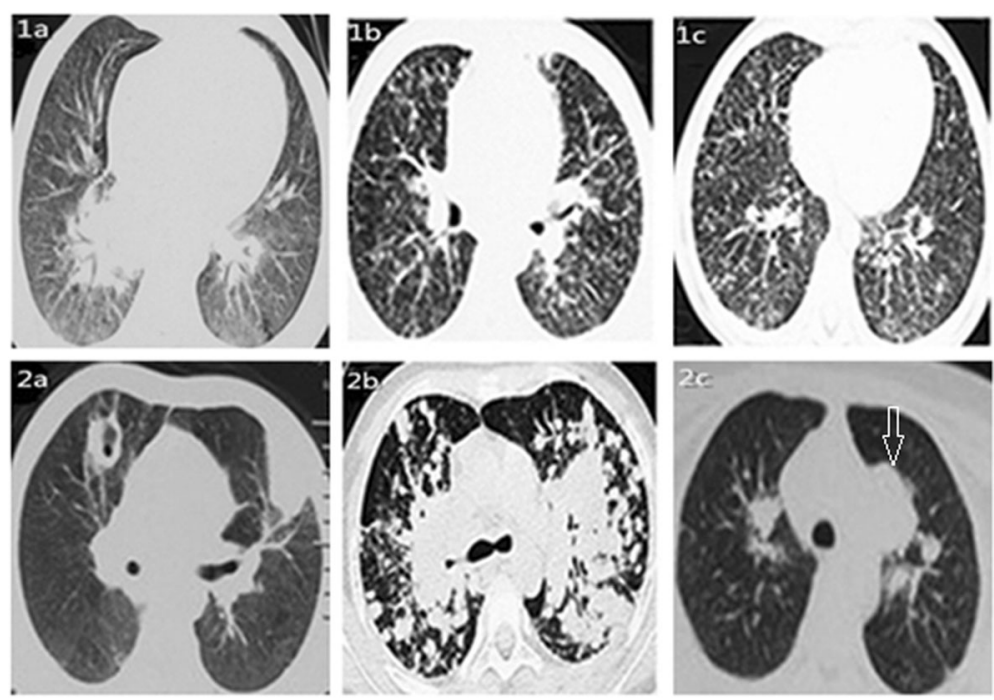

Fig. 1 Chest HRCT scans showing the presence of diffuse nodular opacities and slight ground-glass in bilateral inferior fields (1a; on admission) and consolidation in left upper lobe and cavity in right upper lobe (2a; after treatment for three weeks) in case 1; bilaterally diffuse ill-defined centrilobular nodules and slight ground-glass ( $1 \mathrm{~b}$; on admission) and multi-nodules fused into pieces more in upper lung (2b; after treatment for 3 weeks) in case 2; and bilaterally diffuse ill-defined centrilobular nodules and slight ground-glass (1c; on admission), consolidation with halo (arrow) in left upper lobe (2c; after treatment for one month) in case 3

reactions for pneumocystis jirovecii. After exclusion of infectious agents, diagnosis of mimicking HP probably due to inhalation of rotten fruit elements was made. Treatment with $1 \mathrm{mg} / \mathrm{kg} /$ day prednisone was initiated and clinical symptoms improved after 3 days.

Three weeks after the beginning of tapered prednisone, he developed fever and cough with purulent sputum. HRCT found consolidation in left upper lobe and cavity in right upper lobe (Fig. 2a). Sputum culture was positive for A. fumigatus three times. Parenteral voriconazole therapy for 2 months followed by oral

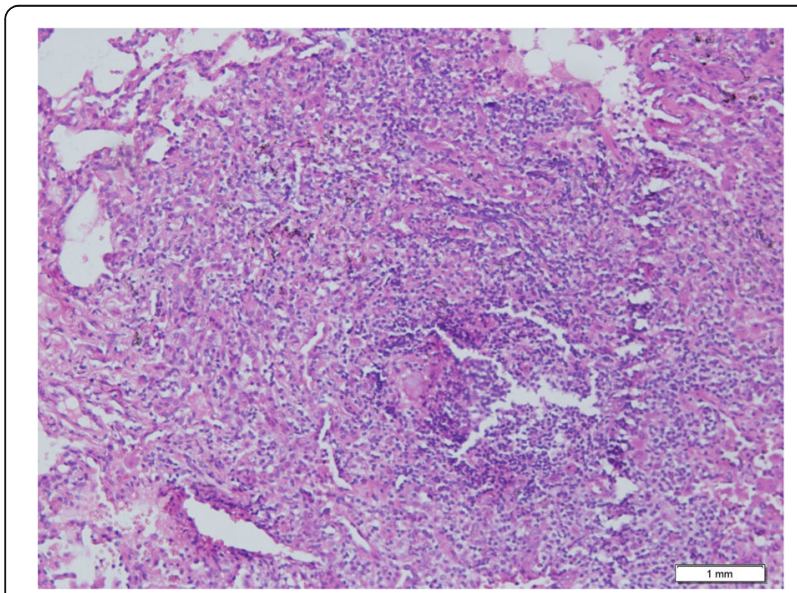

Fig. 2 Pathological findings of lung biopsy (original $\times 200$ ) showing bronchiolo centric lymphocytic infiltrates and non-necrotizing granulomas in lung tissue (case 1) voriconazole was administered for 6 months until lung lesions disappeared completely. In consideration of the patient's progressive course, he was referred to immunological test. Dihydrorhodamine-1,2,3 (DHR) test showed the absence of neutrophil oxidative burst consistent with CGD. Gene mutation analyses revealed compound heterozygous mutations (c.278A $>\mathrm{T}$ and c.475delA) in NCF2 gene, indicating autosomal recessive CGD [8]. Continuous prophylactic treatment with trimethoprimsulfamethoxazole and itraconazole were administered, and no infection recurred in a follow-up period of 4 years.

\section{Case 2}

An 8-year-old girl was admitted to the hospital on February 15, 2015 because of high spiking fever and chills, dry cough, progressive dyspnea and chest stuffy for 20 days. Twenty-four days ago she had burned decayed cornhusks with her brother (case 3 ) for $4 \mathrm{~h}$. She had a history of severe eczema and seasonal rhinitis at 3 years old.

On admission, her oxygen saturation at rest was $93 \%$, and decreased to $84 \%$ after walking. Bilateral basilar rales were noted on auscultation. HRCT scan showed the presence of bilaterally diffuse centrilobular nodules and slight ground-glass (Fig. 1b). BALF from her right middle lobe consisted of $41 \%$ macrophages, $3 \%$ eosinophils and $56 \% \mathrm{~T}$ cells, with a $\mathrm{CD} 4^{+} / \mathrm{CD} 8^{+}$ratio of 0.65 . Fungal and mycobacterial cultures of BALF were negative. The diagnosis of mimicking $\mathrm{HP}$ was made. A treatment of $1 \mathrm{mg} / \mathrm{kg} /$ day prednisone was initiated, and clinical symptoms improved after 2 days. 
As prednisone being tapered after 3 weeks, she developed fever, racking cough with purulent sputum and chest stuffy. Repeated HRCT showed multi-nodules bilaterally distributed along bronchi and part of multinodule fused into pieces more in upper lung (Fig. 2b). Specific IgG antibody to A. fumigatus was positive. Both culture of sputum and BALF from right middle lobe found A. fumigatus. Amphotericin liposome B was taken for 2 months followed by oral voriconazole for one year. The nodes disappeared and the pieces shrank. In consideration of the fact that his brother had a history of perianal abscess and was diagnosed as CGD by means of an abnormal DHR test, she was referred to DHR test, which was consistent with CGD. Sequencing of genomic DNA revealed homozygous mutation (c.541delG) in NCF1 gene, indicating autosomal recessive CGD [9]. Continuous prophylactic antibiotic treatment was administered, and no symptoms recurred anymore.

\section{Case 3}

A 5-year-old boy with high spiking fever and chills, dry cough and progressive dyspnea was admitted to the hospital at the same time with his sister (case 2). He had the same exposure to decayed cornhusks. He had a history of perianal abscess and severe eczema at 3 months old, and no history of previous pneumonia, asthma, or exercise intolerance.

On admission, his oxygen saturation at rest was 95\%, and decreased to $87 \%$ after walking. Bilateral basilar rales were noted on auscultation. HRCT revealed bilaterally diffuse ill-defined centrilobular nodules and slight ground-glass (Fig. 1c). Lymphocytosis of $50 \%$ with a $\mathrm{CD}^{+} / \mathrm{CD}^{+}$ratio of $0.73,48 \%$ macrophages and $2 \%$ neutrophils were shown in BALF. Fungal and mycobacterial cultures for BALF were negative. The diagnosis of mimicking HP was made. Treatment with $1 \mathrm{mg} / \mathrm{kg} /$ day oral prednisone was initiated and clinical symptoms improved after 3 days. A slow taper of prednisone was continued after 3 weeks.

Despite the lack of aggravated symptoms, specific IgG antibody to $A$. fumigatus was positive and his chest HRCT revealed a nodular consolidation with halo sign in left upper lobe (Fig. 2c). Oral voriconazole was taken for 4 months. The halo disappeared and the consolidation shrank. In consideration of his history of perianal abscess, he was referred to DHR test, and the result was consistent with CGD. He was subsequently confirmed to have the same NCF1 gene mutation as his sister. Prophylactic antibiotic treatment was continuously administered. No extra symptoms occurred anymore.

The clinical data relating to $\mathrm{HP}$ and IPAI of the 3 cases are summarized in Table 1. Antecedent history and genetic tests for CGD are summarized in Table 2.

\section{Discussion}

In CGD patients, hypersensitivity to Aspergillus clinically manifested as HP and ABPA occurs after exposure to a variety of antigens, and is characterized by the constitutional symptoms and non-necrotizing granulomas in walls of alveoli and airways. However, HP as the first manifestation of CGD is rare in children.

Our cases illustrate that they had the clinical presentations similar to HP, including the history of exposure to potential inciting antigens, lymphocytosis in BALF, compatible image features, poorly formed granulomas on lung biopsy in one patient (case 1), and a favorable response to systemic glucocorticoids. However, these patients did not fully meet the diagnostic criteria for HP published by Venkatesh and Wild [10].

Lung biopsy in one patient (case 1) revealed nonnecrotizing granulomatous pneumonitis with variable airspace organization. It is necessary to rule out the pulmonary granulomatous process related to the underlying CGD. Granulomas in patients with CGD are typically small, containing central neutrophil micro-abcesses surrounded by epithelioid histiocytes and giant cells and spreading in airways or lung parenchyma [11, 12]. Unlike CGD, the granulomas of our patient were loosely formed and relatively larger, spread through airway to lymph tract, and did not contain central micro-abcesses, similar to the adult CGD patient reported by Katsuya and colleagues [5].

Recently, Esenboga et al. reported that a 16-year-old patient atypically presented with chronic HP caused by close contact with pigeons and exposure to their allergens before the diagnosis of CGD caused by homozygous deletion mutation in NCF1 [13]. Like the present cases, the patient recovered by allergen avoidance combining with the use of anti-inflammatory drug. Meanwhile in another study that followed up 33 patients with X-linked CGD for 10 years, four patients developed interstitial lung disease (ILD). Two of the four patients, one 20 years old and the other 23 years old, were diagnosed with HP through CT images and histopathological examination, probably caused by breathing in dust in a plant and an unknown antigen, respectively [14]. However, the clinical symptoms in the two patients were mitigated only by allergen avoidance, suggesting that CGD patients are more susceptible to hyperinflammation resulting from inhalation of antigens.

The combination of HP/ABPA features has been described in 2 CGD patients with a gradually progressive course over many years $[6,7]$. Interestingly, case 2 had the ABPA features of elevated total serum IgE (3000 IU/mL). However, in ABPA patients, acute course or exacerbation may present nodular pulmonary infiltrates, centrilobular nodules and bronchiectasis on HRCT [15]. Lymphocytosis in BALF is uncommon in ABPA. 
Table 1 Clinical, physiological, radiographical, and pathological data relating to mimicking HP and IPAI in the 3 CGD patients

\begin{tabular}{llll}
\hline CGD patient & Case 1 & Case 2 & Case 3 \\
\hline Age $(y r)$ & 4 & 8 & 5 \\
Sex & male & female & male
\end{tabular}

Data of mimicking HP

Exposure to an offending environment

Symptom/sign

Pulmonary function

Chest HRCT scan

BALF cells

Lung biopsy

Bacterial/viral/fungal cultures

Treatment

Data of IPAI

HRCT scan finding

Bacterial/viral/fungal cultures

Treatment
Antigens probably relating to rotten fruits

Dry cough, dyspnea, fever, bilateral basilar rales

FEV1, 0.48 L (51.2\% predicted); FVC, $0.65 \mathrm{~L}$ (68.3\% predicted)

Diffuse nodular opacities and slight ground-glass in bilateral inferior field

AM: 46\%; Lym: 52\%; Eos: 2\%; $\mathrm{CD}^{+} / \mathrm{CD}^{+}: 0.62$

Bronchiolo centric lymphocytic, non-necrotizing granulomas and no evidence of fungal or bacterial elements

Negative

$1 \mathrm{mg} / \mathrm{kg} / \mathrm{d}$ prednisone

Consolidation in left upper lobe and cavity in right upper lobe

\section{A. fumigatus}

Infusion of voriconazole for 2 months followed by oral voriconazole for 6 months
Antigens probably in musty cornhusks

Spiking fever with chills, dry cough, dyspnea, chest stuffy, bilateral basilar rales

FEV1, 0.8 L (58.7\% predicted); FVC, 0.92 L (58.9\% predicted); $\mathrm{DLCO}, 6.46 \mathrm{ml} / \mathrm{min} / \mathrm{mmHg}$ (46.6\% predicted)

Bilaterally diffuse ill-defined centrilobular nodules and slight ground-glass

AM: 41\%; Lym: 56\%; Eos: 3\%; $\mathrm{CD}^{+} / \mathrm{CD}^{+}: 0.65$

Not available

Negative

$1 \mathrm{mg} / \mathrm{kg} / \mathrm{d}$ prednisone

Multi-nodules bilaterally distributed along bronchi and part of multi-nodules fused into pieces more in upper lung

\section{A. fumigatus}

Infusion of amphotericin liposome B for 2 months followed by oral voriconazole for one year
Antigens probably in musty cornhusks

Spiking fever with chills, dry cough, dyspnea, bilateral basilar rales

FEV1, 0.59 L (57.3\% predicted); FVC, 0.72 L (70.5\% predicted)

Bilaterally diffuse ill-defined centrilobular nodules and slight ground-glass

AM: 48\%; Lym: 50\%; Neu: 2\%; $\mathrm{CD}^{+} / \mathrm{CD}^{+}: 0.73$

Not available

Negative

$1 \mathrm{mg} / \mathrm{kg} / \mathrm{d}$ prednisone

A nodular consolidation with halo sign in left upper lobe

\section{A. fumigatus}

Oral voriconazole for 4 months

HP hypersensitivity pneumonitis, IPAI invasive pulmonary A.fumigatus infection, HRCT high-resolution computer tomography, BALF bronchoalveolar lavage fluid, AM Alveolar macrophages, Lym lymphocytes, Neu neutrophils, Eos eosinophils, FEV1 forced expiratory volume in one second, FVC forced vital capacity, DLCO decreased lung diffusion of carbon monoxide

Table 2 Clinical, radiographical, laboratory and genetic data for CGD of the 3 patients

\begin{tabular}{|c|c|c|c|}
\hline CGD patient & Case 1 & Case 2 & Case 3 \\
\hline Antecedent history & $\begin{array}{l}\text { Pneumonia at } 3 \text { months old, eczema } \\
\text { and seasonal rhinitis at one year old }\end{array}$ & $\begin{array}{l}\text { Eczema and seasonal rhinitis at } \\
3 \text { years old }\end{array}$ & $\begin{array}{l}\text { Perianal abscesses and eczema } \\
\text { at } 3 \text { months old }\end{array}$ \\
\hline lgs & $\begin{array}{l}\operatorname{lgG} 12.2 \mathrm{~g} / \mathrm{L}, \operatorname{lgM} 1.72 \mathrm{~g} / \mathrm{L}, \lg A 2.59 \mathrm{~g} / \mathrm{L} \\
\operatorname{lgE} 598.9 \mathrm{IU} / \mathrm{mL}\end{array}$ & $\begin{array}{l}\operatorname{lgG} 26.8 \mathrm{~g} / \mathrm{L}, \operatorname{lgM} 1.12 \mathrm{~g} / \mathrm{L} \\
\operatorname{lgA} 4.55 \mathrm{~g} / \mathrm{L}, \operatorname{lgE} 3000 \mathrm{IU} / \mathrm{mL}\end{array}$ & $\begin{array}{l}\operatorname{lgG} 26.6 \mathrm{~g} / \mathrm{L}, \operatorname{lgM} 1.29 \mathrm{~g} / \mathrm{L} \\
\operatorname{lgA} 4.23 \mathrm{~g} / \mathrm{L}, \operatorname{lgE} 365.9 \mathrm{IU} / \mathrm{mL}\end{array}$ \\
\hline $\begin{array}{l}\text { Lymphocyte subsets } \\
\text { in peripheral blood }\end{array}$ & $\begin{array}{l}\text { NK cells }(9.3 \%) \text {, B cell }(11.9 \%) \text {; CD } 4^{+} \text {cells } \\
(43.2 \%), \text { CD } 8^{+} \text {cells }(32.85 \%)\end{array}$ & $\begin{array}{l}\text { NK cells }(4 \%), \text { B cell }(14 \%) ; \\
\text { CD4 }{ }^{+} \text {cells }(39 \%), \text { CD8 } 8^{+} \text {cells (37\%) }\end{array}$ & $\begin{array}{l}\text { NK cells }(11 \%), \text { B cell }(17 \%) \text {; } \\
\text { CD4 }^{+} \text {cells }(33 \%), \text { CD }^{+} \text {cells }(36 \%)\end{array}$ \\
\hline DHR test & $\begin{array}{l}\text { No uptake in neutrophil oxidative burst } \\
\text { after phorbolmyristate acetate stimulation }\end{array}$ & $\begin{array}{l}\text { No uptake in neutrophil oxidative } \\
\text { burst after phorbolmyristate } \\
\text { acetate stimulation }\end{array}$ & $\begin{array}{l}\text { No uptake in neutrophil oxidative } \\
\text { burst after phorbolmyristate } \\
\text { acetate stimulation }\end{array}$ \\
\hline Gene mutation & $\begin{array}{l}\text { NCF2 gene (compound heterozygosity } \\
\text { mutation c. } 278 \mathrm{~A}>T \text { and c. } 475 \mathrm{del} A \text { ) }\end{array}$ & $\begin{array}{l}\text { NCF1 gene (homozygous } \\
\text { mutation c.541delG) }\end{array}$ & $\begin{array}{l}\text { NCF1 gene (homozygous } \\
\text { mutation c. } 541 \text { delG) }\end{array}$ \\
\hline
\end{tabular}

CGD chronic granulomatous disease, DHR dihydrorhodamine-1,2,3, Igs immunoglobulins, NK natural killer 
The mechanisms underlying this hyperinflammation are still under investigation. A plausible explanation is that the reduced ROS cannot adequately inhibit the production of inflammatory cytokines [16], and that this ROS deficit in CGD allows for the continuous production of inflammatory cytokines, resulting in immune dysregulation or hyperinflammation. Thus, one of the effective therapeutic approaches for such hyperinflammation is the use of corticosteroids or immunosuppressive drugs [17]. Indeed, infliximab, a chimeric antibody against tumor necrosis factor- $\alpha$ (TNF $\alpha)$, has shown therapeutic efficacy for refractory CGD colitis, as TNF $\alpha$ is thought to play a critical role in granuloma formation in CGD.

Although the symptoms of HP were improved rapidly after systemic corticosteroid treatment, the present patients suffered worsening disease after 3 weeks' treatment, and the clinical, radiological and positive A. fumigatus culture findings are consistent with the diagnosis of IPAI, which is a major life-threatening infection among CGD patients [18]. There are several reasons for the occurrence of IPAI. Firstly, patients with CGD are prone to develop characteristic invasive fungal infections due to Aspergillus specie. Secondly, prolonged steroids therapy makes a contribution to occurrence of IPAI by increasing the patient's susceptibility to infection. Thirdly, the risk of Aspergillus infections in the present patients is higher than that of other pathogens infections because of the exposure to rotten fruits or decayed cornhusks which are considered as Aspergillus spores-rich environment. The occurrence of IPAI makes it easier to diagnose CGD, but which would be detected much earlier in the inflammatory period.

There are two previous reports of 10 patients who developed fulminant mulch pneumonitis (FMP) as emergency presentation of CGD [19, 20]. Unlike our series, the 10 patients presented acute, rapid, often fatal, invasive aspergillosis symptoms after an identifiable exposure to organic material; culture results were positive for $A s$ pergillus before systemic treatment of glucocorticoids, and 5 of the 10 patients died despite the treatment of antifungals and steroid. Based on the disease duration of the present patients, similar inflammatory responses characterized by lung granuloma formation, lymphocytosis in BALF and Aspergillus specific IgG antibodies could be viewed as the subacute end of the acute FMP spectrum caused by inhalation of variable doses of Aspergillus spores.

The incidence of HP is probably much higher in CGD patients, especially in children. CGD should be first excluded by diagnostic DHR testing before steroids therapy in patient with newly diagnosed HP or mimicking HP. Furthermore, it should be noted that the combined application of antifungal drugs and steroids or other anti-inflammatory drugs is more appropriate from the beginning of the treatment in HP patients with suspected CGD, especially in patients with a history of fungal exposure.

\section{Conclusions}

CGD should be considered in children with HP, even in mimicking HP patients with suggestive inhalation history and negative fungal cultures before steroids therapy. A prompt diagnosis of CGD is essential to enable initiation of prophylactic antibacterial and antifungal therapies.

\section{Abbreviations \\ ABPA: Allergic bronchopulmonary aspergillosis; BALF: Bronchoalveolar lavage fluid; CGD: Chronic granulomatous disease; DHR: Dihydrorhodamine-1,2,3; HP: Hypersensitivity pneumonitis; HRCT: High-resolution computer tomography; IPAI: Invasive pulmonary A.fumigatus infection; TNFa: Tumor necrosis factor-a}

\section{Acknowledgements}

We would like to thank all of the patients and their families for their kind cooperation.

Funding

The study received no funding.

Availability of data and materials

Please contact author for data requests.

Authors' contributions

HLiu supervised the patient care, conceptualized and designed the report, collected the data, and drafted the initial manuscript; $J$ supervised the patient care, collected the data and revised the article; HLi supervised the patient care and collected the data; YP supervised the radiological images; SZ supervised the patient care, conceptualized the report, and reviewed and revised the manuscript. All authors read and approved the final manuscript.

Ethics approval and consent to participate

The research was approved by the Ethics Committee of Beijing Children's Hospital. All patient guardians gave informed consent to the study.

Consent for publication

All patient guardians gave informed consent to the publication of this study.

Competing interests

The authors declare that they have no competing interests.

\section{Publisher's Note}

Springer Nature remains neutral with regard to jurisdictional claims in published maps and institutional affiliations.

\section{Author details}

'Department of Respiratory Medicine, Beijing Children's Hospital, Capital Medical University, National Center for Children's Health, Nanlishi Road 56, Xicheng District, Beijing, China. ${ }^{2}$ Imaging Center, Beijing Children's Hospital, Capital Medical University, National Center for Children's Health, Nanlishi Road 56, Xicheng District, Beijing, China.

Received: 19 June 2017 Accepted: 6 October 2017

Published online: 26 October 2017

References

1. Marks DJ, Miyagi K, Rahman FZ, Novelli M, Bloom SL, Segal AW. Inflammatory bowel disease in CGD reproduces the clinicopathological features of Crohn's disease. Am J Gastroenterol. 2009;104(1):117-24.

2. Morgenstern DE, Gifford MA, Li LL, Doerschuk CM, Dinauer MC. Absence of respiratory burst in $\mathrm{X}$-linked chronic granulomatous disease mice leads to 
abnormalities in both host defense and inflammatory response to Aspergillusfumigatus. J Exp Med. 1997;185(2):207-18.

3. Eppinger TM, Greenberger PA, White DA, Brown AE, Cunningham-Rundles C. Sensitization to Aspergillus species in the congenital neutrophil disorders chronic granulomatous disease and hyper-IgE syndrome. J Allergy Clin Immunol. 1999;104(6):1265-72.

4. Konig G, Baur X, Fruhmann G. Sarcoidosis or extrinsic allergic alveolitis? Respiration. 1981:42(3):150-4.

5. Katsuya Y, Hojo M, Kawai S, Kawai T, Onodera M, Sugiyama H. Chronic granulomatous disease with pulmonary mass-like opacities secondary to hypersensitivity pneumonitis: a case report. J Med Case Rep. 2014;8:242.

6. Segerer F, Morbach H, Hassold N, Kleinert S, Tony HP, Roesler J, et al. A 58-year-old man with respiratory insufficiency after a 50-year history of hypersensitivity pneumonitis and pulmonary Aspergillus infections. J Allergy Clin Immunol Pract. 2013;1(6):677-80.

7. Patiroglu T, Gungor HE, Lazaroski S, Unal E. Chronic granulomatous disease with markedly elevated lgE levels mimicking hyperimmunoglobulin $\mathrm{E}$ syndrome. Acta Microbiol Immunol Hung. 2013;60(2):155-62.

8. Patiño PJ, Rae J, Noack D, Erickson R, Ding J, de Olarte DG, et al. Molecular characterization of autosomal recessive chronic granulomatous disease caused by a defect of the nicotinamide adenine dinucleotide phosphate (reduced form) oxidase component p67-phox. Blood. 1999;94(7):2505-14.

9. Roos D, de Boer M, Köker MY, Dekker J, Singh-Gupta V, Ahlin A, et al. Chronic granulomatous disease caused by mutations other than the common GT deletion in NCF1, the gene encoding the p47phox component of the phagocyte NADPH oxidase. Hum Mutat. 2006;27(12):1218-29.

10. Venkatesh P, Wild L. Hypersensitivity pneumonitis in children. Clinical features, diagnosis, and treatment. Pediatr Drugs. 2005;7(4):235-44.

11. Moskaluk CA, Pogrebniak HW, Pass HI, Gallin Jl, Travis WD. Surgical pathology of the lung in chronic granulomatous disease. Am J Clin Pathol. 1994;102(5):684-91.

12. Corrin B, Nicholson AG. Chronic granulomatous disease. In: Corrin B, Nicholson AG, editors. Pathology of the lungs. 3rd ed. London: Churchill Livingstone; 2011. p. 484-5.

13. Esenboga S, Emiralioglu N, Cagdas D, Erman B, De Boer M, Oguz B, et al. Diagnosis of interstitial lung disease caused by possible hypersensitivity pneumonitis in a child: think CGD. J Clin Immunol. 2017;37(3):269-72.

14. Kawai T, Watanabe N, Yokoyama M, Nakazawa Y, Goto F, Uchiyama T, et al. Interstitial lung disease with multiple microgranulomas in chronic granulomatous disease. J Clin Immunol. 2014;34(8):933-40.

15. Stevens DA, Moss RB, Kurup VP, Knutsen AP, Greenberger P, Judson MA, et al. Allergic bronchopulmonary aspergillosis in cystic fibrosis-state of the art: Cystic Fibrosis Foundation consensus conference. Clin Infect Dis. 2003; 37(Suppl 3):S225-64.

16. van de Veerdonk FL, Smeekens SP, Joosten LA, Kullberg BJ, Dinarello CA van der Meer JW, et al. Reactive oxygen species independent activation of the IL-1 beta inflammasome in cells from patients with chronic granulomatous disease. Proc Natl Acad Sci U S A. 2010;107(7):3030-3.

17. Seger RA. Modern management of chronic granulomatous disease. $\mathrm{Br} J$ Haematol. 2008;140(3):255-66.

18. Kelly J, Pinto A, Whitelaw W, Rorstad O, Bowen T, Matheson D. Fatal Aspergillus pneumonia in chronic granulomatous disease. Am J Clin Pathol. 1986;86(2):235-40.

19. Siddiqui S, Anderson VL, Hilligoss DM, Abinun M, Kuijpers TW, Masur H, et al. Fulminant mulch pneumonitis: an emergency presentation of chronic granulomatous disease. Clin Infect Dis. 2007;45(6):673-81.

20. Ameratunga $\mathrm{R}$, Woon $\mathrm{ST}$, Vyas J, Roberts $\mathrm{S}$. Fulminant mulch pneumonitis in undiagnosed chronic granulomatous disease: a medical emergency. Clin Pediatr (Phila). 2010:49(12):1143-6.

\section{Submit your next manuscript to BioMed Central and we will help you at every step:}

- We accept pre-submission inquiries

- Our selector tool helps you to find the most relevant journal

- We provide round the clock customer support

- Convenient online submission

- Thorough peer review

- Inclusion in PubMed and all major indexing services

- Maximum visibility for your research

Submit your manuscript at www.biomedcentral.com/submit
Biomed Central 